
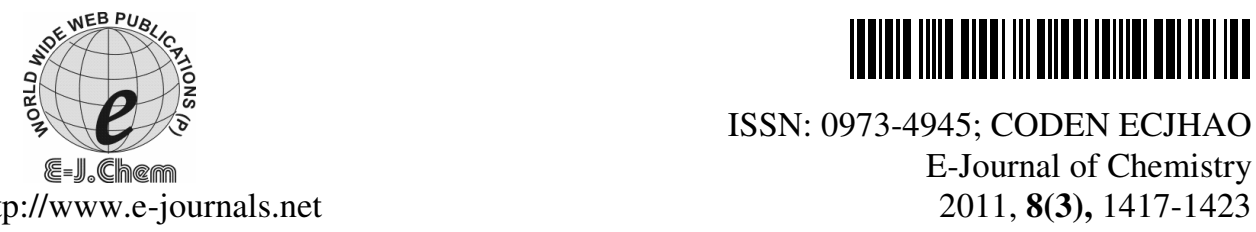

ISSN: 0973-4945; CODEN ECJHAO

E-Journal of Chemistry

http://www.e-journals.net

2011, 8(3), 1417-1423

\title{
Design and Enantiopure Synthesis of (R)-2-((2-Oxooxazolidin-5-yl)methyl)isoindoline- 1, 3-dione: A Key Precursor to Build 2-Oxazolidinone Class of Antibacterial Agents
}

\author{
T. RAJESH ${ }^{\S, \#}$, P. SURYANARAYANA REDDY ${ }^{\S}$, M. MANIDHAR $^{\S}$, \\ M. VIJAYA LAKSHMI and G. MADHUSUDHAN ${ }^{\S *}$
}

${ }^{\S}$ Department of Research and Development Inogent Laboratories Private Limited (A GVK BIO Company)

28A, IDA, Nacharam, Hyderabad-500 076, India

Department of Aanlytical Research and Development

Inogent Laboratories Private Limited, 28A, IDA

Nacharam, Hyderabad-500 076, India

${ }^{*}$ Centre for Pharmaceutical Sciences, Institute of Science and Technology Jawaharlal Nehru Technological University, Kukatpally, Hyderabad-500 072, India

madhusudhan.gutta@inogent.com

Received 29 July 2010; Accepted 6 November 2010

\begin{abstract}
A new synthetic method for the preparation of high enantiopure $(R)$-2-((2-oxooxazolidin-5-yl)methyl)isoindoline-1,3-dione has been developed. The enantiopurity of the obtained $(R)$-2-((2-oxooxazolidin-5-yl)methyl) isoindoline-1,3-dione is established using chiral high performance liquid chromatography (HPLC) i.e. enantiomeric excess (ee) as 100\%. One among the two proposed approaches, is succeeded in preparing enantiopure targeted chiral building block using $(R)$-2-(chloromethyl)oxirane $((R)$-epichlorohydrin) as precursor. This heterocyclic 2-oxazolidinone moiety could be useful to prepare a series of antibacterial agents containing 2-oxazolidinone.
\end{abstract}

Keywords: $(R)$-2-((2-Oxooxazolidin-5-yl)methyl)isoindoline-1,3-dione, Linezolid, Antibacterial agents, Enantiomeric excess, Chiral HPLC.

\section{Introduction}

The antimicrobial properties of 2-oxazolidinone were discovered by researchers at E.I. duPont de Nemours in the 1970 s $^{1}$. In 1978, duPont patented a series of oxazolidinone derivatives as being effective in the treatment of bacterial and fungal plant diseases and in 1984 , another patent described their usefulness in treating bacterial infections in mammals ${ }^{1,2}$. 
In 1987, duPont scientists presented a detailed description of the oxazolidinones as a new class of antibiotics with a novel mechanism of action ${ }^{1,3}$. Pharmacia \& Upjohn (now part of Pfizer) started its own oxazolidinone research program in the 1990s to study structure-activity relationships (SAR) of substituted 2-oxazolidinones led to the development of several subclasses of oxazolidinone derivatives, with varying safety profiles and antimicrobial activity. Two compounds (Figure 1) were considered as drug candidates: eperezolid (PNU-100592) and linezolid (PNU-100766) ${ }^{4,5}$. In preclinical stages of development, they were similar in safety and antibacterial activity, so they were taken to phase I clinical trials to identify any difference in pharmacokinetics ${ }^{6,7}$. Linezolid was found to have a pharmacokinetic advantage requiring only twice-daily dosage, while eperezolid needed to be given thrice a day to achieve similar exposure and therefore only linezolid was preceded to further trials ${ }^{4}$. The U.S. Food and drug administration (FDA) approved linezolid on April 18, 2000 and as of 2009, linezolid is the only oxazolidinone antibiotic available in the market ${ }^{8}$.<smiles>CC(=O)NCC1CN(c2ccc(Br)c(F)c2)C(=O)O1</smiles><smiles>[B]CN1CCN(C(=O)CO)CC1</smiles>

Figure 1. Structures of linezolid and eperezolid

Scientists utilize preferably convergent or linear approach to develop the synthesis of final drug molecules. In linear synthesis, the oxazolidinone skeleton will be constructed in the way of its preparation where as in convergent synthesis initially the oxazolidinone basic moiety will be prepared using readily available chemicals. These basic precursors further connected with other corresponding structural component(s) to build final drug molecules. As in the case of linezolid and also in other oxazolidinone class of antibacterial agents, it is evident that small chiral building blocks are used as key synthetic precursors ${ }^{9-12}$ e.g. $(R)-2-$ ((2-oxooxazolidin-5-yl)methyl)isoindoline-1,3-dione (1), (R)-5-azidomethyl-2-oxazolidinone (2), (S)-glyceraldehyde acetonide (3) etc.( Figure 2).

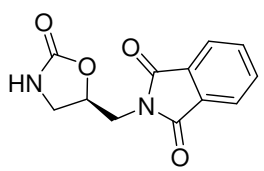

1

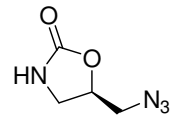

2

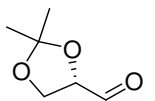

3

Figure 2. Structures of $(R)$-2-((2-oxooxazolidin-5-yl)methyl)isoindoline-1,3-dione (1), $(R)$-5-azidomethyl-2-oxazolidinone (2) and $(S)$-glyceraldehyde acetonide (3).

Our interest in developing the new and efficient synthetic routes for small chiral building blocks $^{11,13}$ in the research area of 2 -oxazolidinones ${ }^{14}$, chosen $(R)-2-((2$-oxooxazolidin-5-yl $)$ methyl)isoindoline-1,3-dione to develop its stereoselective synthesis by using a versatile approach. Several research articles have been published for the synthesis of $(R)$-2-((2-oxooxazolidin-5-yl) methyl)isoindoline-1,3-dione. Firstly, Piper et al. have reported the preparation of racemic 2-((2-oxooxazolidin-5-yl)methyl) isoindoline-1,3-dione (1) starting from 2-((oxiran-2-yl)methyl)isoindoline-1,3-dione using urethane in low yield and also prepared using 2-(3-chloro-2-hydroxypropyl)isoindoline-1,3-dione on reaction with potassium cyanate $(\mathrm{KOCN})$, sodium iodide (NaI), $N, N$-dimethylformamide (DMF) at $100{ }^{\circ} \mathrm{C}$ in $27 \%$ yield $^{15}$. Recently, our research group improved the yield of this reaction to $65 \%$ by transforming the conditions to KOCN, $N, N$-dimethyl aminopyridine ${ }^{14 a}$ (DMAP) in DMF at $120^{\circ} \mathrm{C}$. The $(R)-2-((2-o x o$ oxazolidin-5-yl)methyl)isoindoline-1,3-dione was prepared 
previously from $(R)$-hydroxymethyl-2-oxazolidinones ${ }^{16}$, which was prepared in a multi step synthesis from $D$-malic acid ${ }^{16}$. The $(R)$-compound was also prepared previously by our research group from $(R)$-2-(chloromethyl)oxirane in four steps ${ }^{17}$. In all these research reports, there is no discussion regarding the enantiopurity of the targeted compound.

\section{Experimental}

All reagents and solvents employed were of commercial grade and were used as such, unless otherwise specified. Reaction flasks were oven-dried at $200{ }^{\circ} \mathrm{C}$, flame-dried and flushed with dry nitrogen prior to use. All moisture and air-sensitive reactions were carried out under an atmosphere of dry nitrogen. TLC was performed on Kieselgel 60 F254 silicacoated aluminium plates (Merck) and visualized by UV light $(\lambda=254 \mathrm{~nm})$ or by spraying with a solution of $\mathrm{KMnO}_{4}$. Organic extracts were dried over anhydrous $\mathrm{Na}_{2} \mathrm{SO}_{4}$. Flash chromatography was performed using Kieselgel 60 brand silica gel (230-400 mesh). The melting points were determined in an open capillary tube using a Büchi B-540 melting point instrument and were uncorrected. The IR spectra were obtained on a Nicolet 380 FT-IR instrument (neat for liquids and as $\mathrm{KBr}$ pellets for solids). NMR spectra were recorded with a varian $300 \mathrm{MHz}$ mercury plus spectrometer at $300 \mathrm{MHz}\left({ }^{1} \mathrm{H}\right)$ and at $75 \mathrm{MHz}\left({ }^{13} \mathrm{C}\right)$. Chemical shifts were given in ppm relative to trimethylsilane (TMS). Mass spectra were recorded on waters quattro premier XE triple quadrupole spectrometer using either electron spray ionisation (ESI) or atmospheric pressure chemical ionization (APCI) technique.

\section{Preparation of (R)-5-(chloromethyl)oxazolidin-2-one (5)}

To a stirred solution of $(R)$-2-(Chloromethyl)oxirane $4(5.0 \mathrm{~g}, 0.054 \mathrm{~mol})$ in water $(50 \mathrm{~mL})$, potassium cyanate $(8.76 \mathrm{~g}, 0.108 \mathrm{~mol})$ and magnesium sulfate $(13.0 \mathrm{~g}, 0.108 \mathrm{~mol})$ were added at ambient temperature. The temperature of the reaction mixture was raised to $100{ }^{\circ} \mathrm{C}$ and maintained at the same temperature for $5 \mathrm{~h}$. The reaction mixture was filtered to remove solids and the resulted filtrate was extracted with ethyl acetate $(2 \times 25 \mathrm{~mL})$. The combined organic layer was washed with saturated sodium chloride solution $(25 \mathrm{~mL})$, dried over anhydrous sodium sulfate and the solvent was removed by evaporation under reduced pressure. The obtained solid was triturated with $n$-hexane and filtered to give $(R)$-5-(chloromethyl) oxazolidin-2-one (5) as a white solid (75\% yield); mp 67-68 ${ }^{\circ} \mathrm{C}$.

${ }^{1} \mathrm{H}$ NMR $\left(\mathrm{CDCl}_{3}\right)$ : $\delta 3.5-3.6(\mathrm{~m}, 1 \mathrm{H}), 3.65-3.8(\mathrm{~m}, 3 \mathrm{H}), 4.8(\mathrm{~m}, 1 \mathrm{H}, \mathrm{C} 5-\mathrm{H}), 5.8(\mathrm{br} \mathrm{s}, N \mathrm{H})$; ${ }^{13} \mathrm{C}$ NMR (DMSO- $\left.d_{6}\right): \delta 42.6,46.3,73.9,158.3$; ESI-MS $(\mathrm{m} / \mathrm{z}): 117,135\left(30, \mathrm{M}^{+}+1\right)$; IR $(\mathrm{KBr}): v 3363(\mathrm{NH}), 1746(\mathrm{C}=\mathrm{O}) \mathrm{cm}^{-1}$.

\section{Preparation of (R)-2-((2-oxooxazolidin-5-yl)methyl)isoindoline-1,3-dione (1) (Scheme 1)}

To a solution of $(R)$-5-(chloromethyl)oxazolidin-2-one, 5 (0.5 g, 0.0037 moles) in DMF $(5 \mathrm{~mL})$, potassium phthalimide $(0.683 \mathrm{~g}, 0.0037$ moles $)$ and catalytic amount of triethylbenzylammonium chloride were added. The reaction mixture was stirred at $80{ }^{\circ} \mathrm{C}$ for $12 \mathrm{~h}$. After completion of the reaction, the reaction mixture was poured into water $(20 \mathrm{~mL})$ and extracted with ethyl acetate $(3 \times 30 \mathrm{~mL})$. The combined organic extract was washed with water $(2 \times 20 \mathrm{~mL})$ and evaporated. The obtained solid was stirred in IPA $(15 \mathrm{~mL})$ to get (R)-2-((5)-2-oxo-5-oxazolidinyl)methyl)- $1 H$-isoindole-1,3(2H)-dione (1) as a white solid (85\% yield); m.p. $195-97{ }^{\circ} \mathrm{C}$; Chiral purity $90.4 \%$.

${ }^{1} \mathrm{H} \mathrm{NMR}\left(\mathrm{CDCl}_{3}\right): \delta 3.3(\mathrm{~m}, 1 \mathrm{H}), 3.6(\mathrm{t}, 1 \mathrm{H}), 3.8(\mathrm{~m}, 2 \mathrm{H}), 4.8(\mathrm{~m}, 1 \mathrm{H}), 7.5(\mathrm{~s}, 1 \mathrm{H},-\mathrm{NH}$, $\mathrm{D}_{2} \mathrm{O}$ exchangeable), 7.8-7.95 (m, 4H, Ar-H.); ${ }^{13} \mathrm{C}$ NMR (DMSO- $\left.d_{6}\right)$ : 40.6, 42.9, 72.5, 123.2, 131.4, 134.5, 158.2, 167.7; ESI-MS (m/z): $247\left(\mathrm{M}^{+}+1\right)$; IR $(\mathrm{KBr}): v 3305(\mathrm{NH}), 1749$ $(\mathrm{C}=\mathrm{O}), 1715(\mathrm{C}=\mathrm{O}) \mathrm{cm}^{-1}$. 
Preparation of (R)-1-azido-3-chloropropan-2-ol (6)

$(R)$-2-(Chloromethyl)oxirane $4(10 \mathrm{~g}, 0.108 \mathrm{~mol})$ was dissolved in an aqueous solution of sodium azide $(36.5 \mathrm{~g}, 0.562 \mathrm{~mol}$ in $100 \mathrm{~mL}), 100 \mathrm{~mL}$ acetic acid then added and the solution stirred for $5 \mathrm{~h}$ at $30{ }^{\circ} \mathrm{C}$. The solution was extracted with ethyl aceate $(3 \times 50 \mathrm{~mL})$. The combined organic layer was washed with saturated $\mathrm{NaHCO}_{3}$ followed by water. The organic phase was dried over $\mathrm{Na}_{2} \mathrm{SO}_{4}$, the solvent was removed on a rotary evaporator and the residue was purified by using chromatography on silica gel ( $n$-hexane:EtOAc, 97:3) afforded (S)-1-azido-3-chloropropan-2-ol as a pale yellow colored thick liquid (65\% yield).

${ }^{1} \mathrm{H}$ NMR $\left(\mathrm{CDCl}_{3}\right): \delta 2.45\left(\mathrm{~s}, 1 \mathrm{H},-\mathrm{OH}, \mathrm{D}_{2} \mathrm{O}\right.$ exchangeable), 3.4-3.65 (m, 4H, $-\mathrm{CH}_{2} \mathrm{~N}_{3}$ and $\left.-\mathrm{CH}_{2} \mathrm{Cl}\right), 4.0(\mathrm{~m}, 1 \mathrm{H},-\mathrm{CHOH})$; IR $(\mathrm{KBr}): v 3400(\mathrm{OH}), 2118\left(\mathrm{~N}_{3}\right) \mathrm{cm}^{-1}$; ESI-MS $(\mathrm{m} / \mathrm{z})$ : $136\left(\mathrm{M}^{+}+1\right)$.

\section{Preparation of (R)-2-(3-azido-2-hydroxypropyl)isoindoline-1,3-dione (7)}

To a solution of $(R)$-1-azido-3-chloropropan-2-ol, 6 (2.5 g, 0.0184 moles) in DMF (10 mL), potassium phthalimide $(3.4 \mathrm{~g}, 0.0184$ moles) and catalytic amount of triethylbenzylammonium chloride were added and the mixture stirred at $80^{\circ} \mathrm{C}$ for $12 \mathrm{~h}$. The reaction mixture was poured into water $(25 \mathrm{~mL})$ and extracted with ethyl acetate $(3 \times 50 \mathrm{~mL})$. The combined organic extract was washed with water $(2 \times 25 \mathrm{~mL})$ and evaporated. The obtained solid was stirred in pet. Ether to get $(R)$-2-(3-azido-2-hydroxypropyl)isoindoline-1,3-dione 7 as a white solid (85\% yield); m.p. $65-67^{\circ} \mathrm{C}$;

${ }^{1} \mathrm{H}$ NMR $\left(\mathrm{CDCl}_{3}\right): \delta 3.1$ (br s, $1 \mathrm{H},-\mathrm{OH}, \mathrm{D}_{2} \mathrm{O}$ exchangeable), $3.5(\mathrm{~m}, 2 \mathrm{H}), 3.9(\mathrm{~m}, 2 \mathrm{H})$, $4.2(\mathrm{~m}, 1 \mathrm{H}), 7.8-8.0(\mathrm{~m}, 4 \mathrm{H})$; IR $(\mathrm{KBr}): v 3500(\mathrm{OH}), 2091\left(\mathrm{~N}_{3}\right), 1775(\mathrm{C}=\mathrm{O}), 1711(\mathrm{C}=\mathrm{O})$ $\mathrm{cm}^{-1} ; \mathrm{MS}: \mathrm{m} / z(\mathrm{M}+1) 247$.

Preparation of (R)-2-((2-oxooxazolidin-5-yl)methyl)isoindoline-1,3-dione (1) (Scheme 2)

A solution of the (R)-2-(3-azido-2-hydroxypropyl) isoindoline-1,3-dione (2.0 g, 0.0085 moles) and $\mathrm{Ph}_{3} \mathrm{P}\left(2.67 \mathrm{~g}, 0.0102\right.$ moles) in toluene was stirred under a $\mathrm{CO}_{2}$ atmosphere (5-6 psi, $\mathrm{CO}_{2}$ balloon) at $0{ }^{\circ} \mathrm{C}$. The reaction mass was allowed to stir at $\mathrm{RT}$ and then heated to $100{ }^{\circ} \mathrm{C}$ for $7 \mathrm{~h}$. After completion of the reaction, the reaction mixture was concentrated and the obtained crude product was purified by flash column chromatography to yield the $(R)-2-((5)-2$-oxo -5-oxazolidinyl)methyl)- $1 H$-isoindole-1,3(2H)-dione; $91.6 \%$ yield; chiral purity $100 \%$ (100\% ee); The spectral data are in accordance with the above.

\section{Results and Discussion}

Herein we wish to report a new and efficient synthesis of $(R)-2-((2-0 x o o x a z o l i d i n-5-y l) m e t h y l)$ isoindoline-1,3-dione (1) using commercially available $(R)$-2-(chloromethyl)oxirane (4) (epichlorohydrin). The key challenge of the synthesis is achieving high enantiopurity of the targeted compound. Initially, we designed a two step synthesis to accomplish our goal. The first step involves the straight away transformation of the starting material, $(R)$-2-(chloromethyl) oxirane into $(R)$-5-(chloromethyl)oxazolidin-2-one (5) by following the reported procedure with minor modification which includes introduction of $\mathrm{MgSO}_{4}$ in the reaction condition. The obtained $(R)$-5-(chloromethyl)oxazolidin-2-one was converted to the required compound $\mathbf{1}$ by reaction with potassium phthalimide in DMF under PTC condition (Scheme 1).

To analyze the resulted $(R)$-2-((2-oxooxazolidin-5-yl)methyl)isoindoline-1,3-dione using chiral high performance liquid chromatography (chiral HPLC), initially analytical method was established with racemic 2-((2-oxooxazolidin-5-yl)methyl)isoindoline-1,3-dione which is prepared from racemic 2-(chloromethyl)oxirane. 


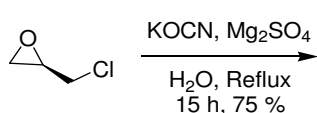

4

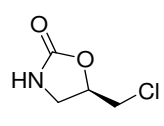

5

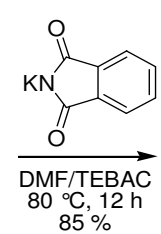

Scheme 1

\section{Chiral HPLC method}

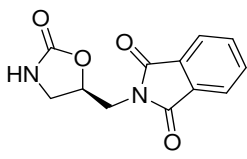

1

A Shimadzu Class-VP V6.14SP1 separation module equipped with Shimadzu UV detector was used. The analysis was carried out on chiral pack ASH, $250 \times 4.6,5 \mu$ with mobile phase $n$-hexane and ethanol in the ratio of 30:70 (filter and degas through $0.45 \mu$ membrane filter paper) program; isocratic elution was used with UV detection at $200 \mathrm{~nm}$ at flow rate of 1.0 $\mathrm{mL} / \mathrm{min}$. The column temperature was maintained as ambient. The data was recorded using Shimadzu Class-VP software (run time-30 min).
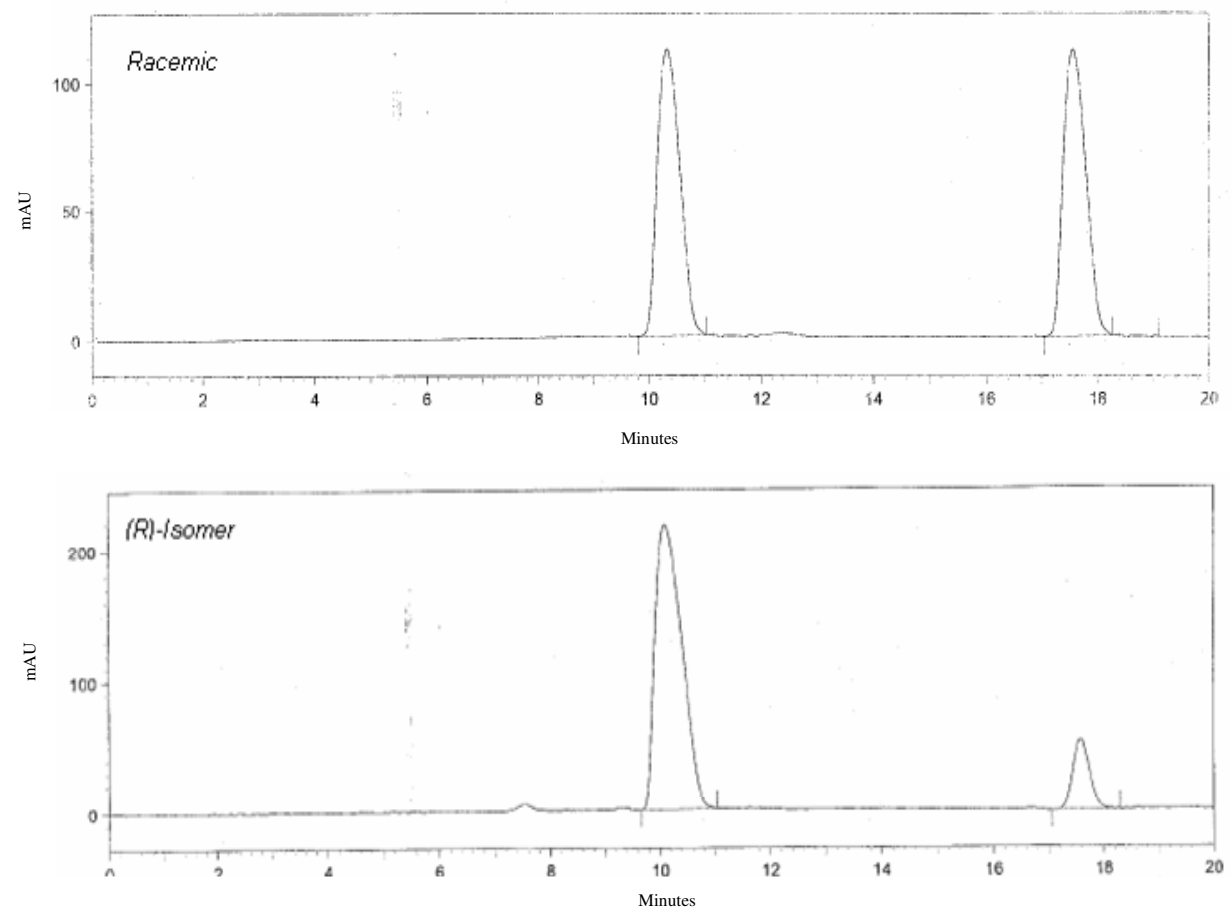

Figure 3. Chiral HPLC chromatograms of racemic and $(R)$-2-((2-oxooxazolidin-5-yl) methyl)isoindoline-1,3-dione (chiral purity: 90.4\%)

Even though, the described synthetic approach (Scheme 1) is high yielding but unfortunately the prepared $(R)$-compound, 1 shows the low enantiopurity, 90.4\% and we have not further carried out any research on this approach to determine how and where the racemization might happen.

Immediately, we switched our attention on alternative routes. The $(R)$-2-(chloromethyl) oxirane is regarded as starting material even in the alternative route. $(R)$-Epichlorohydrin, 4 was stereo selectively ring-opened with $\mathrm{NaN}_{3}$ in $\mathrm{AcOH}$, whilst maintaining acidic condition, 
to give (2R)-1-azido-3-chloropropan-2-ol (6) without racemization. The azido alcohol 6 on treatment with phthalimide in $\mathrm{N}, \mathrm{N}$-dimethylformamide at $100{ }^{\circ} \mathrm{C}$ yielded the corresponding $(R)$-1-azido-3-chloropropan-2-ol (7) which on treatment with $\mathrm{Ph}_{3} \mathrm{P}$ and carbondioxide in toluene under reflux gave the required $(R)-2$-((2-oxooxazolidin-5-yl)methyl)isoindoline-1,3dione. Even though the second synthetic approach is longer in steps (three step synthesis) as compared to Scheme 1, no other isomer was detected when we analyzed, using chiral HPLC, $(R)$-compound resulted using Scheme 2.

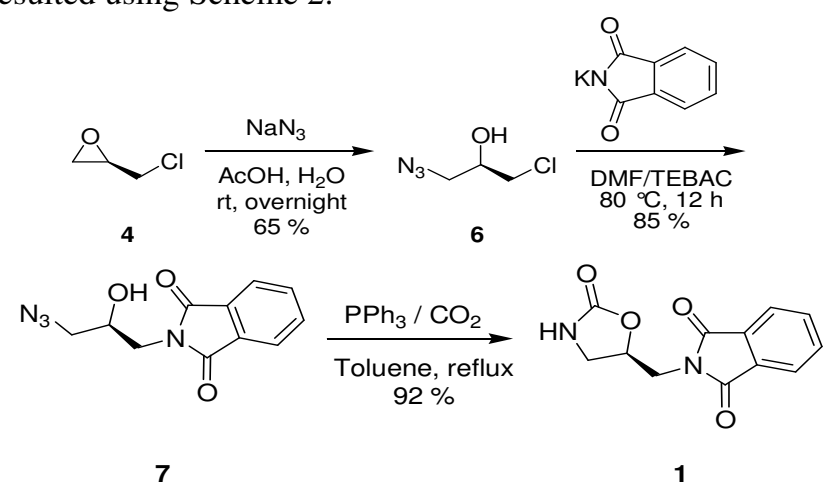

Scheme 2. High enantiopure synthesis of $(R)$-2-((2-oxooxazolidin-5-yl)methyl)isoindoline1,3-dione

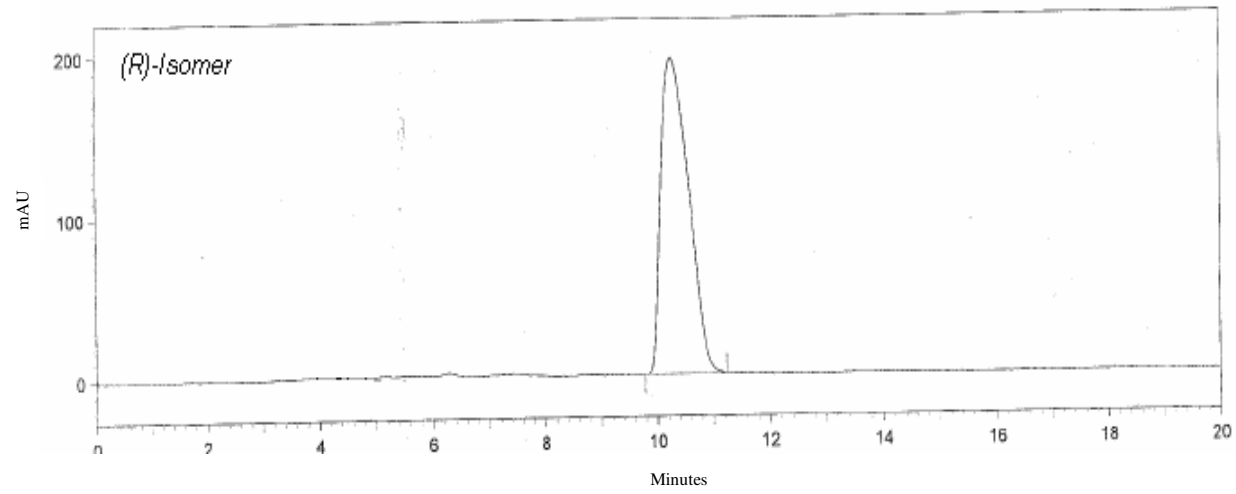

Figure 4. Chiral HPLC chromatogram of $(R)$-2-((2-oxooxazolidin-5-yl)methyl)isoindoline1,3-dione obtained in Scheme 2 (chiral purity 100\%)

\section{Acknowledgment}

The authors thank Inogent Laboratories Private Limited (A GVK BIO Company) for the financial support and encouragement.

\section{References}

1. Brickner S J, Curr Pharm Des., 1996, 2, 175-194.

2. Moellering R C, Ann Intern Med., 2003, 138, 135

3. Slee A M, Wuonola M A and McRipley R J, Zajac I, Zawada M J, Bartholomew P T, Gregory W A and Forbes M, Antimicrob Agents Chemother., 1987, 31, 1791.

4. Barbachyn M R and Ford C W, Angew Chem Int Edn., 2003, 42, 2010-2023.

5. French G, J Antimicrob Chemother., 2003, 51 (Suppl 2), ii45-ii53. 
6. Livermore D M, J Antimicrob Chemother., 2000, 46, 347-350.

7. Ford C W, Zurenko G E and Barbachyn M R, Curr Drug Targets Infect Disord., 2001, 1, 181.

8. Livermore D M, Mushtaq S, Warner M and Woodford N, J Antimicrob Chemother., 2009, 63, 713-715.

9. Madar D J, Kopecka H, Pireh D, Pease J, Pliushchev M, Sciotti R J, Wiedeman P E and Djuric S W, Tetrahedron Lett., 2001, 42, 3681.

10. Sciotti R, Pliushchev M, Wiedeman P E, Balli D, Flamm R, Nilius A M, Marsh K, Stolarik D, Olly R, Ulrich R and Djuric S W, Bioorg Med Chem Lett., 2002, 12, 2121.

11. Madhusudhan G, Om Reddy G, Rajesh T, Ramanatham J and Dubey P K, Tetrahedron Lett., 2008, 49, 3060.

12. Guang Y-X, Yi Z and Man C Xu, Chin Chem Lett., 2006, 17, 302.

13. Chandra Babu K, Ramadasu G, Gangaiah L, Madhusudhan G and Mukkanti K, Indian J Chem., 2010, 49B, 260.

14. Chinnam Naidu K, Ravi Babu G, Gangaiah L, Mukkanti K and Madhusudhan G, Tetrahedron Lett., 2010, 51, 1226-1229.

15. Piper J R, Rose L M, Johnston T P and Grenan M M, J Med Chem., 1979, 22(6), 631-639.

16. (a) Madar D J, Kopecka H, Pireh D, Pease J, Pliushchev M, Sciotti R J, Wiedeman P E and Djuric S W, Tetrahedron Lett., 2001, 42, 3681; (b) Sciotti R, Pliushchev M, Wiedeman P E, Balli D, Flamm R, Nilius A M, Marsh K, Stolarik D, Olly R, Ulrich R and Djuric S W, Bioorg Med Chem Lett., 2002, 12, 2121.

17. Madhusudhan G, Om Reddy G, Ramanatham J and Dubey P K, Indian J Chem., 2006, 45B, 1264-1268. 


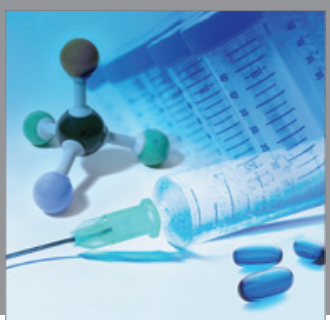

International Journal of

Medicinal Chemistry

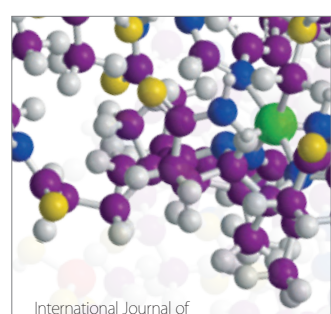

Carbohydrate Chemistry

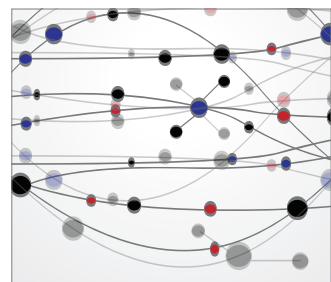

The Scientific World Journal
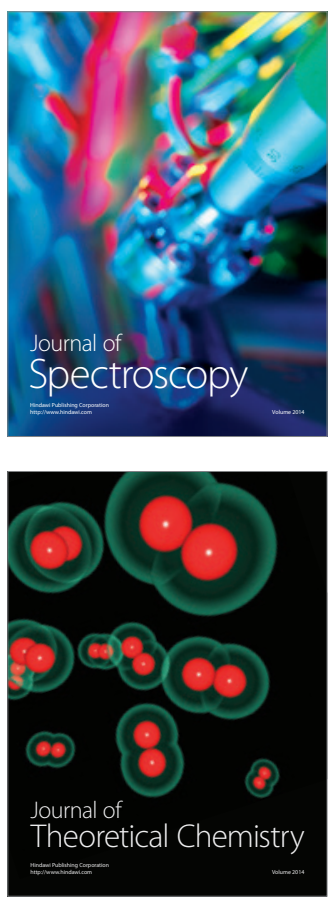
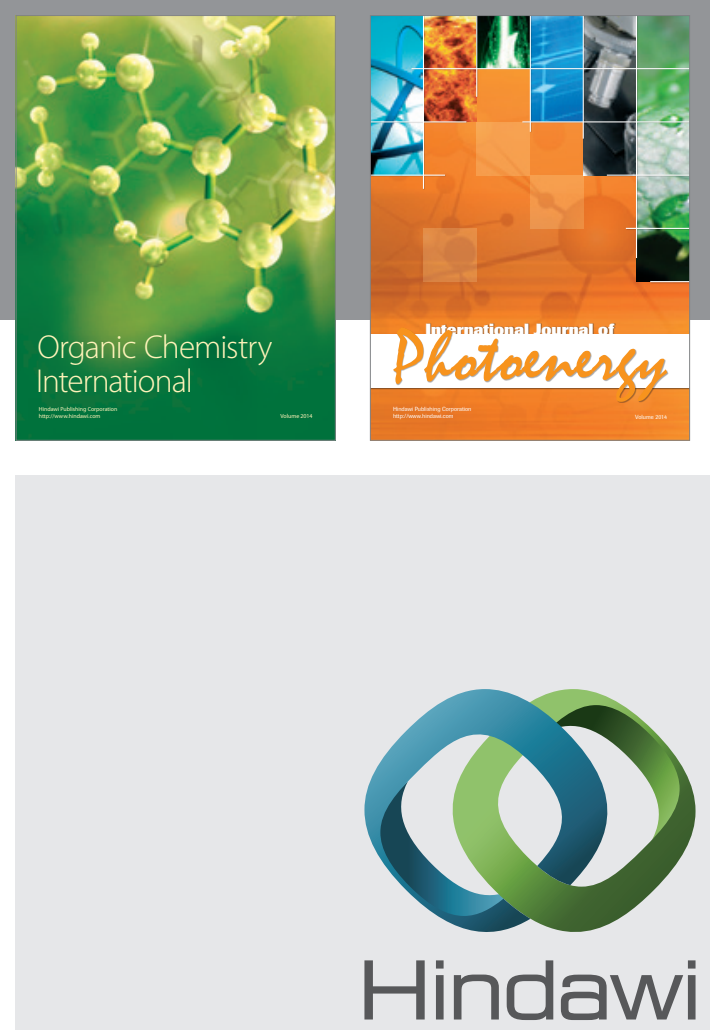

Submit your manuscripts at

http://www.hindawi.com
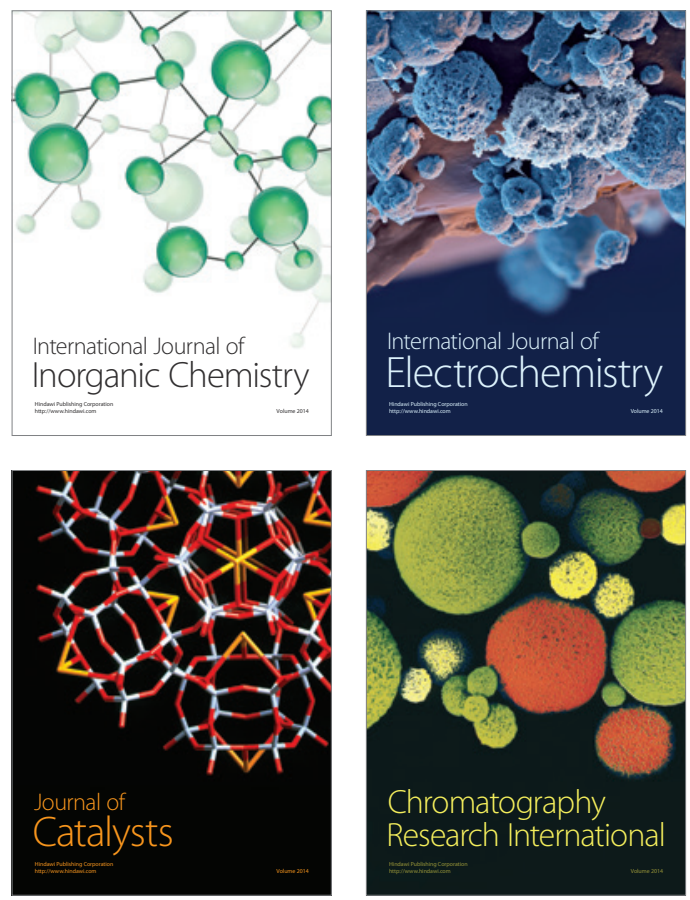
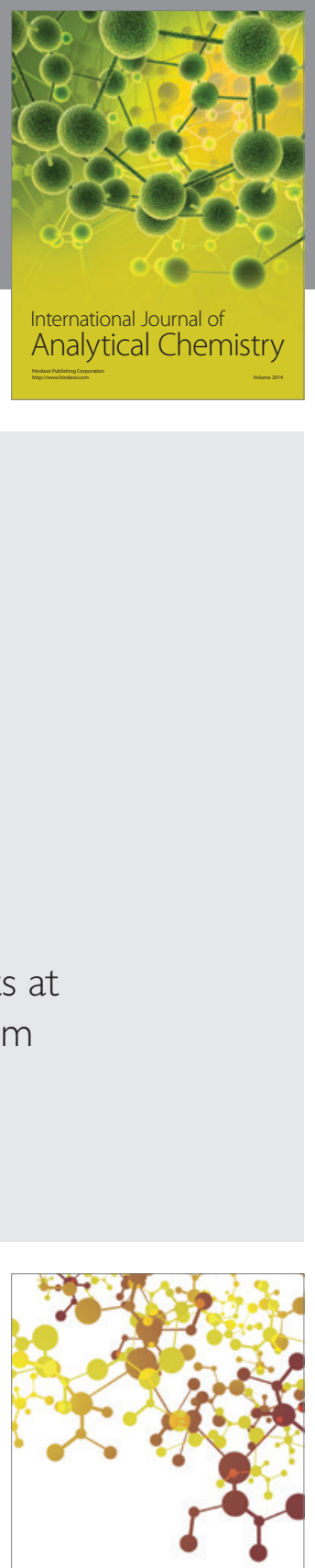

Journal of

Applied Chemistry
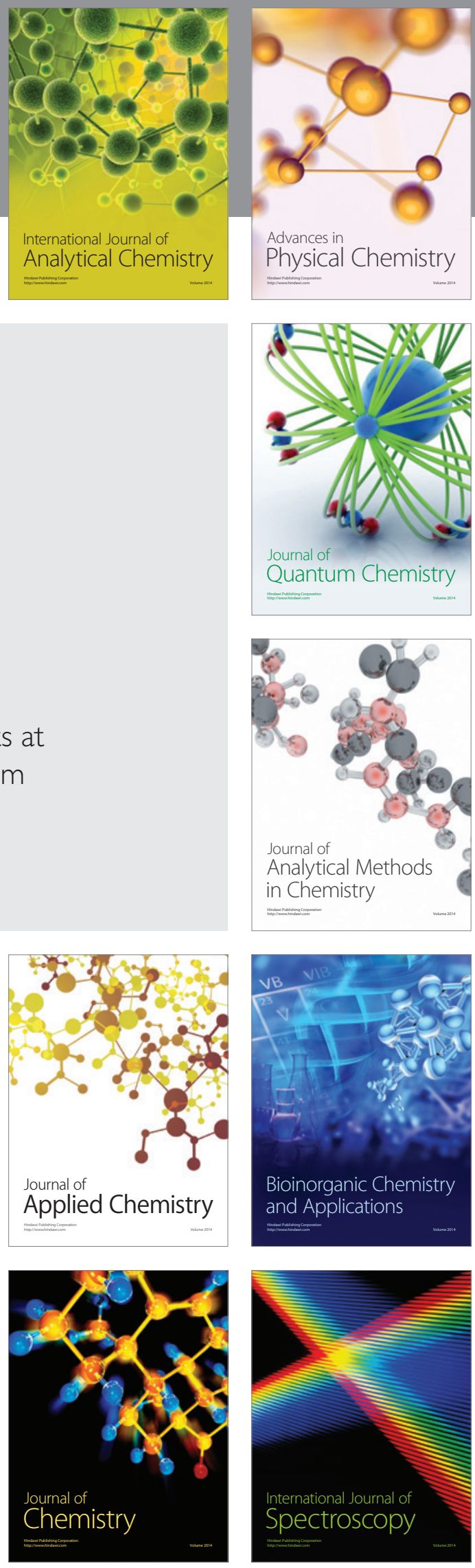